\title{
16 THE RECONSTRUCTION OF PORTABLE COMPUTERS: On the Flexibility of Mobile Computing in Mobile Activities
}

\author{
Gamel O. Wiredu \\ Interaction Design Centre \\ Department of Computer Science and Information Systems \\ University of Limerick \\ Limerick Ireland
}

\begin{abstract}
The remote distribution of contemporary activities has direct implications for the mobility of humans and associated actions. Remote distribution inherently entails parameters such as the mobility of individuals, artifacts, tasks, and information; and potential conflicts between objective and personal motives of individuals. The interactions of these parameters bear directly on the range of mobile computing services derivable from the use of these artefacts. Based on an activity-theoretical perspective, this paper presents a discussion of the dynamics of mobile computing services through an analysis of the process of reconstruction of personal digital assistants (PDAs) in a mobility-saturated work-integrated learning project. Upon this analysis, the flexibility of mobile computing as a direct function of the reconstruction process is discussed and a conceptual framework for the analysis of flexible mobile computing in mobile activities proposed.
\end{abstract}

Keywords Reconstruction, motives, flexibility, mobile computing

\section{INTRODUCTION}

Portable information and communication technologies (ICTs) have invaded us, and human activities are increasingly being mobihized and distributed. Yet the present level of mobility and distribution is so seldom problematized, so often taken for granted within IS research (Sørensen 1999). Mobility presents a significant challenge for IS 
research which, in the past, has largely concerned itself with desktop ICTs such as mainframe and desktop computers.

More significantly, the remote distribution of contemporary activities has direct implications for the mobility of humans and associated computing actions. Remote distribution inherently entails parameters such as the mobility of individuals, artifacts, tasks, and information; and potential conflicts between objective and personal motives. For instance, how professionals compute in mobile or distributed environments with portable ICTs, as well as the dynamics of how they reconstruct these artifacts as they derive mobile computing services, has seen little investigation and clarification in the literature. This paper takes up the challenge to tease out the dynamics of mobile computing services through an analysis of the process of reconstruction of personal digital assistants (PDAs) in a mobility-saturated work-integrated learning project. It is aimed at theorizing the flexibility of mobile computing based on an understanding of the reconstruction of portable computers.

The next section is a brief discussion of the theoretical foundations of this task, followed by a description of the empirical study and its relevant findings. Analysis of the findings follows and concludes with the proposition of a conceptual model of flexible computing.

\section{THEORETICAL FOUNDATIONS}

\subsection{Motives and the Theory of Activity}

The theory of activity' is a "philosophical and cross-disciplinary framework for studying different forms of human practices as development processes, with both individual and social levels interlinked at the same time" (Kuuttin 1995, p. 25). Activity theory originates in Vygotsky's (1978) idea of the mediated stimulus-sign-response relationship which is transformed into a subject-tool-object relationship by Engeström (1987): the subject's responses to external object stimuli are mediated by psychological tools and signs.

In any conscious human activity at the individual level, there is a subject who pursues an object with a motive to transform the subject and object into an outcome, a product. It is these transformations that motivate the existence of the activity. At the social level, where the individual performs an activity in collaboration with other people, an activity is more complex because of its collective nature. In his theory of expansive learning, Engeström drew on Marx's (1867) and Zinchenko's (1983) knowledge of the economics of human labor to remodel the subject-tool-object structure to reflect the

'Although the historical roots of activity theory are traced to various sources by various contemporary authors, it is mostly claimed that its foundation was laid in the cultural-historical psychological works of Lev Vygotsky during the 1920s and early 1930s. However, the understanding of activity in the works of psychologists such as Vygotsky, Leont'ev, Engeström, and Ilyenkov is inspired by Karl Marx. 
collective nature of an activity. The resultant activity system incorporates the community-based elements of human activity: subject, tools, object, rules, community, division of labor, and outcome.

In this system, the relationship between the subject and the object are mediated by tools in addition to interactions with community members and the rules governing the division of labor among community members. Engeström's conceptualizations suggest that all the elements of the structure are interconnected and they shape each other based on a transition from human adaptation to consumption. An activity is directed by a motive, and the motive is to transform an object: an activity "answers a definite need of the subject, is directed toward an object of this need, is extinguished as a result of its satisfaction, and is produced again, perhaps in other, altogether changed conditions" (Leont'ev 1978, p. 62). The motivation is aroused when the person has identified an object which he or she perceives will satisfy his or her need. The motive is a result of stimulation in the consciousness of the subject by biologically and sociologically satisfying external objects; it gives an activity a determined direction. The motive, according to Leont'ev, may be "either real or ideal, either present in perception or exclusively in the imagination or in thought" (p. 62). The general macro structure of an activity incorporates both internal and external activities of the subject; it is constituted by a series of conscious and goal-oriented actions which are also constituted by subconscious operations.

A series of actions together constitute an activity, and they are conducted through a planning-orientation-execution phase. This implies that actions are performed consciously and are directed at the achievement of immediate or intermediate goals. Generally, goal-oriented actions result in objective products which satisfy the motives by which an activity was stimulated.

Compared with actions that are consciously performed, operations are subconsciously performed. An operation is determined by the goal which is given in certain conditions requiring a certain mode of action, and operations can degenerate into actions when the subject encounters adverse conditions in an activity. The back-and-forth movements and transformation of actions and operations have direct implications for the analysis of the flexibility of computing actions.

\subsection{Mobility Modalities and Technology Affordances}

The uses of mediating physical and psychological tools may constitute activities, or may constitute actions and operations of an activity depending on the pertaining conditions. In other words, the analysis of mediation by physical instruments has to open up to the fact that the instrument can assume any of the activity levels depending on several other environmental conditions that impact directly or indirectly on the activity. The identification and analysis of the dynamic properties of physical tools are particularly important when one considers the complexity of modern portable ICTs. To understand this problem, we draw upon Kristofferson and Ljungberg's (2000) argument that the utility of portable ICTs is dependent on three factors: modality, environment, and application. The immediate nature of the physical and social surroundings defines 
the environment; applications represent the design properties of ICTs such as hardware, software and data; and modality stands for the fundamental patterns of human movement. Thus, the ease and/or clumsiness of their uses are, primarily, factors of conditions representing the modalities of human mobility and their affordances (based on the user's perception of their physical, interface, and system design properties).

Modality, in the sense of Kristoffersen and Ljungberg, is the description of the fundamental patterns of motion of humans as they move around: traveling, visiting, and wandering. Traveling is the process of movement from one point to another in which the distance between those two points is such that a vehicle is required to convey the person in the process. Visiting demands some form of traveling but its essential component is the prolonged time a person spends at one location to perform some function before moving to another location. A wanderer is a person whose movements exhibit "extensive local mobility in a building or local area" (p. 142). He or she does some limited traveling and visiting in a localized environment. These fundamental patterns represent a modest and simple functional characterization of the complexly variegated nature of human mobility; however, they are useful in the sense of their intrinsic linkage with portable ICTs and the conditions of their use.

According to Gibson (1979), the affordances of an object of the environment, natural or artificial, are the perceptible properties it "offers the animal, what it provides or furnishes, either for good or ill" (p. 127). Affordances point to both the environment and the observer, and are realized in the interaction between organisms and environmental objects.

An affordance cuts across the dichotomy of subjective-objective and helps us to understand its inadequacy. It is equally a fact of the environment and a fact of behavior. It is both physical and psychical, yet neither. An affordance points both ways, to the environment and to the observer (Gibson 1979, p. 129).

ICTs may have affordances for information capture, processing, and transmission, and their ease of use is very much dependent on perceived ease of use in action. Therefore, "making affordances perceptible is one approach to designing easily-used systems" (Gaver 1991, p. 2). It follows from this that ICT affordances are derived from their physical, interface, and system design properties, from previous information based on socio-cultural experience, and are founded on the motives of the activities they mediate.

Socio-cultural experience is premised on the objective and social sense of external objects as demonstrated in Ilyenkov's (1977) analysis of the concept of the ideal. The ideal is a sign or symbol historically and culturally built collectively by society for society which mediates human activities. The ideal

confronts the individual as the thought of preceding generations realized ("reified," "objectified," "alienated") in sensuously perceptible "matter"-in language and visually perceptible images, in books and statues, in wood and bronze, in the form of places of worship and instruments of labor, in the 
designs of machines and state buildings, in the patterns of scientific and moral systems, and so on. All these objects are in their existence, in their "present being" substantial, "material," but in their essence, in their origin they are "ideal," because they embody the collective thinking of people, the "universal spirit" of mankind" (Ilyenkov 1977; emphasis added).

Thus, there is a distinction between crude material matter of natural origin and idealized material of socio-cultural origin built through the collective sense-making of people.

These parameters - motives driving an activity, technology affordances, and modalities of human mobility - have some bearing on the degrees of reconstruction of ICTs by users, and reflect the enabling and limiting capacities of ICTs.

\subsection{Technology Reconstruction}

Reconstruction of technology is based on a user's teleological "assignment-or imposition-of function" to the artifact (Searle 1995, p. 14) and it is the accumulation or individual reconstructions that evolve into a socially shared understanding seen as a social construction (Berger and Luckmann 1967; Searle 1995). The enabling and limiting capacities of ICTs can be situated within arguments founded on technological determinism and social constructivism which provide contrasting insights about the nature of technology in human activities. Technological determinists (e.g., Winner $1997,1993,2001$ ) argue in favor of the imposing nature of technology, that technology invites human action and not the other way round. Thus, one can perform many actions with a car, but one cannot fly the car like an airplane. The social constructivists (e.g., Bijker 2001; Bijker et al. 1987; MacKenzie and Wajcman 1985; Orlikowski 1992, 2000; Woolgar 1991), on the other hand, argue for the supple nature of technology systems based on the social context of use.

While the technological determinists seem to base their arguments mostly on the design properties of technology, the social constructivists seem to base their arguments on the activity- or context-based interpretation of the design properties of technology. But technology possesses both determining or limiting and socially constructed or enabling properties. Technology is both imposing and flexible, both a determinant of actions and socially constructed.

It is reasonable to say that actions are constrained by the physical properties of technology, and moreover the "situated use of technology is confined to a set of predefined options and reflects the instantiation of a context-free logic embedded in the artifact" (Kallinikos 2002, p. 291). However, it is also reasonable to say, at the same time, that an overemphasis of technological determinism can be misleading because technology is interpretively flexible. Bijker (2001), for example, argues that "this interpretive flexibility... shows that neither an artifact's identity nor its technical 'success' or 'failure,' are intrinsic properties of the artifact but subject to social variables" (p. 26). This implies that particular affordances of an artifact and the modalities in which it is used can induce a flexible interpretation and reconstruction of the its properties. 


\section{MOBILE COMPUTING IN MOBILE WORK- INTEGRATED LEARNING: AN EMPIRICAL STUDY}

\subsection{Information Management Through Mobile Computing}

A 12-month empirical study of mobile computing in a work-integrated learning (WIL) project in the National Health Service of the United Kingdom commencing in April 2003 was undertaken to understand the complexities of portable technology use in mobile activities.

This was a pilot project in which 12 health professionals were being trained for a new professional role in surgical care. The new role was being created to fill an impending man-hour or skills shortage gap which would be caused when the weekly hours of junior doctors were cut from an average of 72 to 56 by the European Union Working Time Directive.

The project was characterized by remote distribution and mobility - of the 12 trainees/learners, of the learning activity, of the PDAs, and of information. It entailed both local mobility within each learner's hospital and remote mobility to and from the training coordination center in London. In the parlance of Kristoffersen and Ljungberg (2000), these forms of mobility are respectively conceptualized as wandering and visiting. PDAs were officially adopted and deployed to provide computational support for this activity. Particularly, the highly critical issues of monitoring and remote control of the learners' activities in their individual hospitals and the development of learning portfolios were the targets of the computing support.

Remote monitoring and control of clinical actions, and the development of portfolios of evidence of those actions undertaken, were requirements whose fulfillment was aimed at satisfying two parties. First, the sponsors of the project, the European Union, had to be supplied with reports and statistics of proceedings of the training project. These reports would convey the details of the activities that were actually undertaken by the learners in their hospitals with the aim of underlining the credibility of the whole training exercise and hence of the new professional role. Second, the wider community of existing medical professionals had to be satisfied that this new professional role was credible. Since professions in the medical field have existed for centuries, the success of this new profession depended on the acceptance and trust given by existing medical professionals. Thus, the portfolios were meant to provide evidence of the depth and breadth of learning activities undertaken by the learners in the event anyone doubted their relevance.

Each learner was provided with a Compaq iPAQ H3970 model PDA which was running a Pocket PC 2002 operating system. Each was also given a foldable keyboard to facilitate their input of written reflections-on-action (Schön 1983). This PDA model has an inbuilt appointment calendar, address book, and limited or "pocket" versions of Microsoft $\circledast$ Word $($, Excel $\AA$, and Outlook $($. These were deployed to be used by the learners as tools for capturing information on the spot, for reading information, for recording clinical and learning activities, for writing reflections right after every learning 
activity, for sharing information, and for transfer of relevant data to the monitoring center in London. The PDAs were supposed to be used to process notes and other information while roaming from one ward to another and in other locations of the hospitals as training demanded. Crucial to the learning process was to record what was done when it was done, not at the end, and the PDAs were deployed to fulfil immediate and easy capture and processing of information.

An activity logging database with recorded details of patient encounters on the wards was to be developed by each trainee. Clinical activities were to be selected from a predefined "pick list" through tapping a stylus directly on the PDA screen. Additional data included details such as the initials of any supervisor and whether a performed activity was an elective or an emergency. The patient's age and gender were recorded but, in accordance with data protection legislation, their names were not.

There was also a learning reflective journal, which consisted of a set of templates with headings such as "thoughts and feelings?" and "what worked and what didn't?" These were intentionally open-ended questions that would allow the learners to frame the answers as they wished. Answers to these questions were to be typed as reflectionson-actions at the end of each learning day using the foldable keyboard.

It was envisaged that the PDAs would provide learning support to the learners through the accumulation of relevant learning resources-medical literature, drug calculators, and formulary ${ }^{2}$ - which could be available to the learners anywhere during their learning maneuvers. Although access to learning resources was implemented 6 months into the project, it eventually became the key factor that sustained any hope which the learners had in the PDA. Compared with the scenario in which learners have to make visits to libraries to gain access to learning resources, or the one in which the learner is burdened with the task of carrying paper versions of those resources, the PDA would alleviate such problems by saving the time to visit a library and the effort to carry many books while roaming. It was envisioned that when a PDA is inscribed with theoretical medical information and used in practical learning environments, the user/learner could intermittently refer to this information to shape meaning-making from the practical clinical actions.

\subsection{Failure and Success Perceptions}

As far as the training project was concerned, the PDA and all the custom applications that were designed to provide mobile computing support for the learners were deemed as a failure after the implementation period. The artifact could not be used in the clinical setting because of both design and environment condition problems. The systemic design of the PDA itself was a major limitation (low level processors, slower to manipulate, smaller memory, and limited input mechanisms are typical examples). This in turn affected the custom applications that were designed into the PDAs. In the end, the highly mobile nature of clinical duties around the hospital wards ensured that contemporaneous mobile computing was not feasible or possible.

${ }^{2}$ British National Formulary was the particular formulary in this instance. 
For example, the performance of a typical clinical action such as taking a surgical patient's history could not happen contemporaneously with logging of actions into the PDA. Nor could the learner, in the event when he or she was in the company of the surgical team examining patients in the wards, be audacious enough to pull out the PDA to read, take notes, or $\log$ in actions. Apart from the issue of audacity, experiential learning - which relies on direct practice and observation - would not take place in such an instance. From the perspective of interaction, the outcome of Sørensen and Pica's (2005) study of police work in the UK corroborates the fact that portable ICT use onthe-move occurs in "rhythms" between "physical and virtual contexts of work." In other words, more physical work undermines virtual working with a portable artifact and vice versa. It was, therefore, not surprising when the project manager officially called for the abandonment of the PDA as a tool of information management in the project.

Alongside the failure perception, the learners reported that the PDA was an excellent personal organizer which many of them could not "live without." These reports were received during and after the project. It was clear that the custom applicationssuch as calendar, task scheduler, and address book - had proven to be extremely useful as far as personal organization alongside learning activities was concerned. In the final analysis, the learners were ambivalent toward the PDAs.

\section{FLEXIBILITY OF MOBILE COMPUTING}

In respect of this brief case description, the intriguing question is, what are the dynamic conditions which engendered the success-and-failure perception of mobile computing services? First and foremost, it has to be noted that whether a portable ICT is perceived to offer any mobile computing service at all depends on a combination of three factors: the affordances of the artifact, the modalities of human mobility, and the motives of the activities they mediate and which engender their use (Wiredu 2005). The degree of influence of these factors is dynamic. For example, affordances are dependent on factors such as design properties, experience, and previous socio-cultural information; modalities of mobility appear in various forms from extremely remote to local; and changing conditions and needs of people induce them to switch motives. Although the case clearly shows that the design properties of the PDAs offered few affordances, and that mobile computing was inflexible and a failure in the project, it is noteworthy that the learners' final evaluation and perception of the PDA as a wonderful tool was indicative of its ability to satisfy their other personal motives. In order to unveil the dynamics underlying the success-and-failure perception of the artifact, it is interesting to analyze the reconstruction of the artifact, based on its interpretive flexibility (Bijker 2001) within the trajectory of its use, and within the confines of the artifact's deterministic design properties.

\subsection{Ideality and Reconstruction of the PDA}

The trajectory of use of the PDA was situated within the learners' mutating perception of the PDA as a tool or object depending on the activity and motive on the 
one hand, and flexible use on the other hand. As a tool, which was what it was envisioned to be from the outset, it would figuratively represent a transparent screen through which the subject could see the learning object and transform it. As an object, it would represent an opaque device standing between the subject and object: its use would represent another activity existing alongside the learning activity. Evidence from the project suggested that, in terms of the central activity, the device represented an object, an opaque piece of equipment, which interfered with the learners' clinical routines and contravened its initial tool-functionality. The source of this problem is to be found precisely in the idealization of the PDA; that is, the design of PDAs and the marketing gimmicks that promote their diffusion, which influenced their adoption and deployment in the project.

Over the years, the gap between expected and actual use of ICTs have founded many accounts of information systems failure. Expectations of technology success, usually conceived before expensive technology integration projects, are largely informed by the pseudo accomplishments of such technologies. Such information results from the conception of the ideal PDA, of either designers' and hence marketers' touted ease of use or accounts from successful use in entirely different contexts. In the work-integrated learning case, the integration of the PDAs was a result of their perceived ease of use to support activity logging and reflections writing in distance and distributed learning. Since this ideal is a reflection of the designers' construction of these artifacts, and thus their motives, the social variables (Bijker et al. 1987) within the use conditions engendered processes of reconstruction of the PDA and re-conceptualization of its ideal.

The ideal or essence (Ilyenkov 1977) of PDAs at the outset of the project was a simple extrapolation of the ideal functionalities of desktop computers: their automating, informating, and transformating capabilities (Zuboff 1988). Stated differently, the PDA is itself a portable prototype of a desktop computer inputted with miniature versions of desktop computer applications. Even in certain respects, the portability of the PDA gives it an added advantage over desktop computers. One such respect is its mobility, and hence its ostensible facilitation of mobile computing. Here was an extremely volatile and ambitious training project, implementation of which would undoubtedly be characterized by crucial challenges. It would be work-integrated, activity-based, conducted in distant and distributed locations, function under the direct control of surgical staff and hence out of immediate control of the project team, highly locally mobile, confrontational, unstable, and slippery. Since it was a distance and distributed learning exercise, it was imperative for the project team to institute measures to control-to scaffold, monitor, and coordinate-the learners' distant activities. Upon this, the adoption and deployment of the PDAs, based on their ideal, was deemed an efficient controlling and stabilizing measure.

An intriguing aspect of the evidence from the PDA use over the period was its simultaneous rejection and acceptance by the learners. Its nonutility in the clinical setting, software problems, and data losses caused its eventual formal abandonment in the project. As far as the learning activity was concerned, the ideal PDA proved to be illusive in its utility. However, the uses of its generic or standard applications at the personal level proved to be a fantastic experience, a tool that many of the learners could not "live without." Thus, while the perception of the PDA as a learning support tool in the project was a failure, the same device was deemed a success as far as its standard or 


\begin{tabular}{lcr} 
Project Use & reconstruction & Personal Use \\
\hline Low flexible computing & Anti-programming & De-scripting \\
Custom applications & Drifting & High fiexible computing \\
Strong inscriptions & & Generic applications \\
Object (opaque) & & Weak inscriptions \\
High mobility & Tool (transparent) \\
High control & & Low mobility \\
Imposing context & Low control \\
High Complexity & & Less imposing context \\
Failure & Low Complexity \\
& & Success
\end{tabular}

Figure 1. Reconstruction of the PDA

factory-built applications were concerned. Even at the end of the project, by which time the PDA had long been abandoned, the learners found the PDAs useful, but this usefulness lived alongside prior disappointment, signifying ambivalence. It is within this ambivalence, based on the social variables in the context of use, that reconstruction of the PDA is attributable.

To begin with, the fact that the success of a PDA manifests in its usage as an action or operation rather than activity, leading to its perception as a tool rather than an object, has to be emphasized. In other words, the flexibility of mobile computing determines its successful use. To be sure, evidence and accounts of ICT failures coupled with the efforts of IS developers attest to the fact that technology users instinctively desire and strive continuously toward a state of flexible computing. Over the course of the workintegrated learning project, this striving for flexibility on the part of the learners was obvious; circumstances of low flexible computing, symbolizing failure, were continuously being substituted for higher flexible computing. Given that the project-use of the PDA was deemed a failure and personal-use a success, the process of reconstruction from uselessness to usefulness was situated within the continuum between these two sets of uses (see Figure 1).

Specifically, reconstruction was rooted in and embodied by the strength of inscriptions (Akrich 1992) of the original designers and of the project manager. The framework of learning actions and reflections, which underpinned the design of the three different applications, was grounded on pedagogical principles to surrogate the project manager's monitoring and instructions from the training center in London. Given the strong focus of the project on surgical care skills acquisition toward the assumption of junior doctors' functions, and the aim to satisfy accreditation and acceptability requirements, the pedagogical principle underlying the clinical actions and reflections framework was instructive and objectivist-oriented. Hence, the applications that emanated were characterized by strong inscriptions of the project manager's desired patterns of expected use by the learners. These attributes of instructive learning - such as monitoring, scaffolding, and facilitation-were all inscribed into the PDAs based on implicit and explicit assumptions about the technology's capacities, its ideal capacities, for providing mobile computing services. The automation of these attributes, the strong inscriptions, because they were imposing on the users, and because they added to existing structures represented by the design properties of the PDAs and the learning 
conditions, exemplified high complexity and an overload of structures (Sørensen et al. 2002). In short, the PDA could not be idealized as it was desired. In reality, "antiprogramming" (Latour 1991), "de-scripting" (Akrich 1992), and "drifting" (Ciborra 2000) were inevitable.

Instead of activity logging after the completion of every action, the learners, on realizing the clinical impracticality of such actions, used paper-based logging sheets and later transferred these into the PDA when they returned home. Instead of writing reflections-on-action at the end of every day's learning, most of them wrote them weekly; worse still, they wrote on paper before typing into their PDAs. Worst of all, many of them even found it more convenient to perform these computing actions on their desktop computers and subsequently synchronize them into the PDA. It was clear that the learners were following an anti-program. These counter-actions were performed to alleviate the imposition and intrusion associated with the custom application; that is, they were de-scripting the inscribed remote-controlling measures of the project manager-not rebelliously, but in their instinctive orientation toward flexible computing.

The failure of the technology under the custom applications and its success under the standard applications suggest that the learning conditions were more accountable for anti-programming and de-scripting than the design properties. These conditions contained the social variables upon which, Bijker (2001) conceptualizes the interpretive flexibility of technology. In truth, the learners' interpretation of the applications built into the PDA, leading to a mix of success-and-failure perceptions, was premised on whether the learning actions allowed flexible computing or otherwise. In low flexible computing, the PDA was an object. As an object, if it ever satisfied a need, the learners' motive to transform it was implicit in its reconstruction into a tool; its tool perception reflects highly flexible computing which, in the learners' case, could only be accomplished in less mobile and less imposing conditions--at home or after work, for instance. Reconstruction was witnessed in a drift from uselessness in objective circumstances toward successful personal use. Wartofsky (1973) argued similarly:

On this reconstruction, we may speak of a class of artefacts which can come to constitute a relatiely autonomous "world," in which the rules, conventions and outcomes no longer appear directly practical, or which, indeed, seem to constitute an arena of non-practical, or "free" play or game activity.... So called "disinterested" perception, or aesthetic perception, or sheer contemplation then becomes a possibility; but not in the sense that it has no use. Rather, in the sense that the original role of the representation has been, so to speak, suspended or bracketed (p. 208).

It is exactly the phenomena of suspension and bracketing which characterized the reconstruction of the PDA.

Of course the PDA ended up as a tool, but a tool for other personal activities and motives of the learners contrary to the originally purported tool function of the learning activity. To wit, at the collective level of the 12 learners, it was clear that the PDA had been socially constructed-personalized and reconstructed at the individual level—into a useful and successful tool.

It is therefore argued that the set of conditions of an activity, which determine the flexibility of mobile computing, must be the focal point of determining whether an 
artifact offers any mobile computing service. On the balance of the flexibility of mobile computing in the project, the PDA offered optimum computing services during its use in less frustrating conditions (Ortega y Gasset 1941), that is, when it was being used to fulfil personal motives.

\section{HUMAN MOBILITY AND FLEXIBLE COMPUTING: A CONCEPTUAL MODEL}

The preceding arguments shape up into relationships between the various factors which have dominated the analysis: human mobility, motives, conditions, ICT affordances, and flexibility of mobile computing. These relationships are condensed into a conceptual model which suggests a path for analyzing mobile computing in human activities and for ascertaining the flexibility of mobile computing. In view of the murky nature of the concept of mobility, it is necessary to develop this conceptual model to ground the analysis of the impact of portable ICTs as mediators in human activities. Thus, the whole concept of mobility, in terms of portable ICTs and mobile computing, is properly dissected to depict its constituent levels and their interrelationships between these levels (see Figure 2).

The spatial, temporal, and contextual dimensions of mobility are fundamental and inseparable: all other forms, types, or modalities of mobility can be properly understood along the lines of a combination of their space, time, and context dimensions. This inseparability is depicted by the oval that embodies the mobility levels in Figure 2.

It is well known that human mobility is most fundamental due to the purposeful movement of humans caused by their biological and environmental needs. An aspect of this idea can be found in Wiberg's (2001) argument that human mobility is inspired

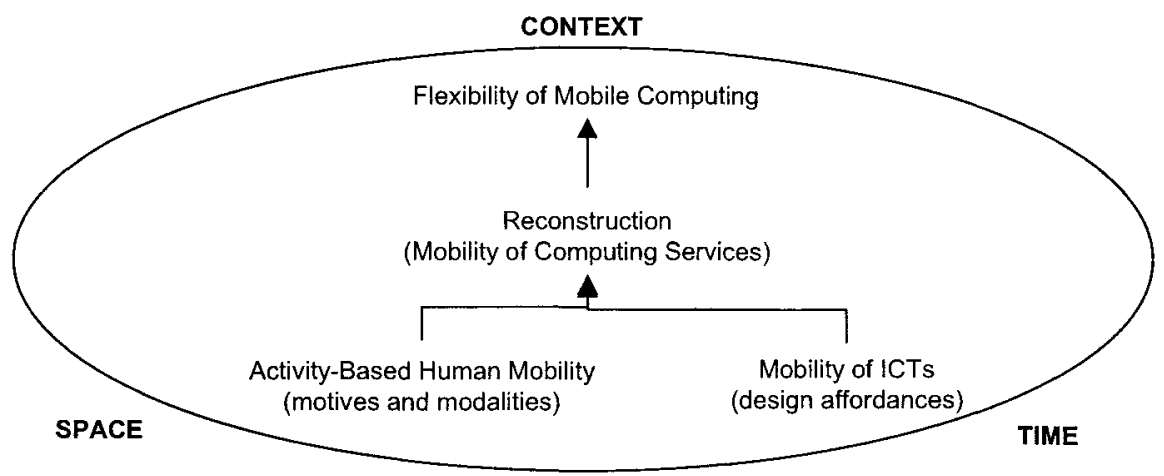

Figure 2. Conceptual Framework for the determination of Flexible Computing from Mobility of Humans Activities and ICTs 
by the social need to interact. While human mobility is basic, an understanding of the mobility of ICTs cannot be achieved when human and object mobility are separated. In other words, since portable ICTs are incapable of self-mobility, understanding their impact relies on understanding the modalities of human mobility that engender the mobility of ICTs: the mobility of ICTs, in the context of purposeful human activities, is always dependent on human mobility. Even though self-moving robotic machines seem to be exceptions, we have to remember that humans design the machines that enable them to exhibit self-mobility. The inseparability of human and object mobility is a result of the ontogenetic and phylogenetic development efforts of individuals and society which stimulate human activities (see Leont'ev 1978, 1981; Marx 1867; Vygotsky 1962, 1978). Objects are either the targets or mediators of human activities, thus they are always intrinsic aspects of activities which embody human movements. Human and object mobility, therefore, serve as a substrate upon which other forms of mobility develop or depend.

Mobile computing services comprise the next level of mobility and are direct resultants of the mobility of ICTs and the conditions within those activities they mediate. Note that whether a portable ICT is perceived to provide any mobile computing service at all depends on a combination of three deciding factors: the affordances of the artifact based on its physical, systemic, and interfacial design properties; the motives that engender their uses; and the modalities of human mobility. These three factors can be derived from a task-technology fit (Goodhue and Thompson 1995) analysis of activitybased human mobility and technology-in-use at the base level of the model.

It may be misleading to argue simplistically that portable ICTs automatically provide mobile computing services. Mobile humans carry portable ICTs to draw on their computing services potentiality for satisfying particular motives in their activities; if the affordances of the ICT, the motives of those activities, and the modalities of human mobility exhibited make it impossible to draw on the information services, then the ICT virtually becomes a white elephant and this engenders the reconstruction process. Since mobile human activities are performed within changing dimensions and modalities of mobility, the degree of accessibility of mobile computing services within mobile artifacts for supporting mobile activities vary considerably (see Weilenmann 2001; Wiberg and Ljungberg 2001). Accessibility resonates well in reconstruction because it is one of reconstruction's key attributes.

Based on the state and quality of mobile computing services that can be obtained from portable ICTs, the flexibility of mobile computing can be deciphered. In the workintegrated learning case, accessibility to computing services shaped the reconstruction and personalization of the PDA, leading to our determination of the flexibility of mobile computing. Furthermore, it is the determination of this flexibility which informs on the transformative impact of a particular ICT in an activity. Portable ICTs mediate activities and transform them into technology-mediated activities. A typical example is the technology transformation of learning into technology-mediated learning (e.g., Alavi and Leidner 2001) and mobile learning which is increasingly attracting attention in current technology-mediated learning research. Work is also increasingly being mobilized in various forms leading to current popular themes such as occupational mobility and mobile professionals (Kakihara and Sørensen 2002), nomadic working (Dahlbom 2000), tele-activities (Castells 2001), and e-lancers (Malone and Laubacher 1998). However, 
mobile computing services are not automatic enhancers of mobile activities (see Weilenmann 2001, Wiberg 2001). In fact they can be corrupters of those activities, just as the "technologizing" of the word, espoused by Ong (1982) and Fichtner (1985), could possibly lead to rote and unproductive learning.

\section{CONCLUSION}

To conclude, for the purposes of analysing the utility of portable ICTs in purposeful human activities, the mobility levels presented in the model, are valuable. The model places the analysis of mobile information services and reconstruction in a pivotal position, brings the complexities and complications associated with the uses of portable ICTs in human activities into focus, and displaces the tendency to oversimplify its problematic nature. The model proposes a shift in perspective from focusing on the factory-based design properties of portable ICTs for making judgements about their utility toward a focus on the mobile computing services they offer in human activities. Hence, it is in the analysis of the reconstruction of the artifact - the causes by affordances, motives and modalities of mobility, as well as the enhancing or debilitating effects on those activities that will unearth a clearer understanding of the flexibility of mobile computing. This is the most effective way of informing the design of portable ICTs for mobilising human activities.

\section{REFERENCES}

Akrich, M. "The De-scription of Technical Objects," in Shaping Technology/Building Society W. E. Bijker E. and J. Law (Eds.), Cambridge, MA: MIT Press, 1992.

Alavi, M., and Leidner, D. E. "Research Commentary: Technology-Mediated Learning - A Call for Greater Depth and Breadth of Research," Information Systems Research (12:1), 2001, pp. $1-10$.

Berger, P. L., and Luckmann, T. The Social Construction of Reality: A Treatise in the Sociology of Knowledge, Harmondsworth, UK: Penguin, 1967.

Bijker, W. E. "Understanding Technology Culture through a Constructivist View of Science, Technology and Society," in Visions of STS: Counterpoints in Science, Technology and Society Studies, S. H. Cutliffe and C. Mitcham (Eds.), Albany, NY: State University of New York Press, 2001.

Bijker, W., Hughes, T., and Pinch, T. The Social Construction of Technology Systems, Cambridge, MA: MIT Press, 1987.

Castells, M. The Internet Galaxy: Reflections on the Internet, Business and Society, NewYork: Oxford University Press, 2001.

Ciborra, C. U. (Ed.). From Control to Drift: The Dynamics of Corporate Information Infrastructures, Oxford, UK: Oxford University Press, 2001.

Dahlbom, B. "Networking: From Infrastructures to Networking," in Planet Internet K. Braa, C. Sorensen, and B. Dahlbom (Eds.), Lund, Sweden: Studentliteratur, 2000.

Engeström, Y. Learning by Expanding: An Activity-Theoretical Approach to Developmental Research, Helsinki: Orienta-Konsultit, 1987.

Fichtner, B. "Learning and Learning Activity," in Education for Cognitive Development, E. Bol, J. P. P. Haenen, and M. Wolters (Eds.), The Hague: SVO/SOO, 1985. 
Gaver, W. "Technology Affordances," in Proceedings of the Computer Human Interaction (CHI 1991), New York: ACM Press, 1991, pp. 79-84.

Gibson, J. J. The Ecological Approach to Visual Perception, Boston: Houghton Mifflin, 1979.

Goodhue, D. L., and Thompson, R. L. "Task-Technology Fit and Individual Performance," MIS Quarterly (19:2), 1995, pp. 341-356.

Ilyenkov, E. V. "The Concept of the Ideal," in Problems of Dialectical Materialism, E. V. Ilyenkov (Ed.), Moscow: Progress Publishers, 1977 (available online at http://www. marxists.org/archive/ilyenkov/works/ideal/ideal.htm).

Kakihara, M., and Sørensen, C. "Post-Modern Professionals' Work and Mobile Technology," in Proceedings of the New Ways of Working in IS Conference: $25^{\text {th }}$ Information Systems Research Seminar in Scandinavia (IRIS25), Denmark: Copenhagen Business School, 2002.

Kallinikos, J. "Reopening the Black Box of Technology Artifacts and Human Agency," in Proceedings of the $23^{\text {rd }}$ International Conference on Information Systems, L. Applegate, R. D. Galliers, and J. I. DeGross, Barcelona, Spain, 2002, pp. 287-294.

Kristoffersen, S., and Ljungberg, F. "Mobility: From Stationary to Mobile Work," in Planet Internet, K. Braa, C. Sorensen, and B. Dahlbom (Eds.), Lund, Sweden: Studentliteratur, 2000.

Kuuttin, K. "Activity Theory as a Potential Framework for Human-Computer Interaction Research," in Context and Consciousness: Activity Theory and Human-Computer Interaction, B. A. Nardi (Ed.), Cambridge, MA: MIT Press, 1995.

Latour, B. "Technology is Society Made Durable," in A Sociology of Monsters: Essays on Power, Technology and Domination, J. Law (Ed.), London: Routledge, 1991, pp. 103-131.

Leont'ev, A. N. Activity, Consciousness and Personality, Englewood Cliffs, NJ: Prentice-Hall, 1978.

Leont'ev, A. N. Problems of the Development of the Mind, Moscow: Progress Publishers, 1981.

MacKenzie, D., and Wajcman, J. (Eds.). The Social Shaping of Technology: How the Refrigerator Got its Hum, Milton Keynes, UK: City University Press, 1985.

Malone, T. W., and Laubacher, R. J. "The Dawn of the E-Lance Economy," Harvard Business Review, September-October 1998, pp. 145-153.

Marx, K. Capital, Volume 1: The Process of Production Capital, Moscow: Progress Publishers, 1867 (available online at http://www.marxists.org/archive/marx/works/1867-cl/index.htm).

Ong, W. J. Orality and Literacy: The Technologizing of the Word, London: Routledge, 1982.

Orlikowski, W. J. "The Duality of Technology: Rethinking the Concept of Technology in Organizations," Organization Science (3:3), 1992, pp. pp. 398-427.

Orlikowski, W. J. "Using Technology and Constituting Structures: A Practice Lens for Studying Technology in Organizations," Organization Science (11:4), 2000, pp. 404-428.

Ortega y Gasset, J. "Man the Technician," in Towards a Philosophy of History, J. Ortega y Gasset (Ed.), New York: W. W. Norton, 1941.

Schön, D. A. The Reflective Practitioner: How Professionals Think in Action, New York: Basic Books, 1983.

Searle, J. The Construction of Social Reality, New York: Free Press, 1995.

Sørensen, C., Mathiassen, L., and Kakihara, M. "Mobile Services: Functional Diversity and Overload," Working Paper \#118, Department of Information Systems, London School of Economics and Political Science, 2002.

Sørensen, C., and Pica, D. "Tales from the Police. Mobile Technologies and Contexts of Work," Information and Organization (15:3), 2005 (forthcoming).

Sørensen, T. "Rush-Hour Blues of the Whistle of Freedom," STS Working Paper, Center for teknologi of samfunn, Norges teknisk-naturvitenskapelige universitet, Trondheim, Norway, 1999.

Vygotsky, L. S. Mind in Society: The Development of Higher Psychological Processes, Cambridge, MA: Harvard University Press, 1978. 
Vygotsky, L. S. Thought and Language, Cambridge, MA: MIT Press, 1962.

Wartofsky, M. "Perception, Representation, and the Forms of Action: Towards an Historical Epistemology," Chapter 11 in Models: Representation and the Scientific Understanding, M. Wartofsky (Ed.), Dordrecht: Reidel, 1973, pp. 188-209.

Weilenmann, A. "Negotiating Use: Making Sense of Mobile Technology," Personal and Ubiquitous Computing (5:2), 2001, pp. 137-145.

Wiberg, M. "Knowledge Management in Mobile CSCW: Evaluation Results of a Mobile Physical/Virtual Meeting Support System," in Proceedings of the $34^{\text {th }}$ Hawaii International Conference on System Science, Los Alamitos, CA: IEEE Computer Society Press, 2001.

Wiberg, M., and Ljungberg, F. 'Exploring the Vision of 'Anytime, Anywhere,' in the Context of Mobile Work," in Knowledge Management and Virtual Organizations, Y. Malhotra (Ed.), Hershey, PA: Idea Group Publishing, 2001, pp. 157-169.

Winner, L. Autonomous Technology. Technics-Out-of-Control as a Theme in Political Thought, Cambridge, MA: MIT Press, 1977.

Winner, L. "Upon Opening the Black Box and Finding it Empty: Social Constructivism and The Philosophy of Technology," Science, Technology and Social Values (18), 1993, pp. 362-378.

Winner, L. "Where Technological Determinism Went," in Visions of STS: Counterpoints in Science, Technology and Society Studies, S. H. Cutliffe and C. Mitcham (Eds.), Albany, NJ: State University of New York Press, 2001.

Wiredu, G. O. Mobile Computing in Work-Integrated Learning: Problems of Remotely Distributed Activities and Technology Use, Unpublished Ph.D. Thesis, Department of Information Systems, London School of Economics, University of London, 2005.

Woolgar, S. "The Turn to Technology in Social Studies of Science," Science, Technology and Human Values (16:1), 1991, pp. 20-50.

Zinchenko, P. I. "The Problem of Involuntary Memory," Soviet Psychology (12:2), 1983, pp. 55111.

Zuboff, S. In the Age of the Smart Machine: The Future of Work and Power, New York: Basic Books, 1988.

\section{ABOUT THE AUTHOR}

Gamel O. Wiredu is a research fellow at the Interaction Design Centre of the Department of Computer Science and Information Systems at the University of Limerick, Ireland. He holds M.Sc. and Ph.D. degrees in Information Systems from the London School of Economics. His doctoral research centered on mobile computing in remotely distributed activities in which he investigated the motivational, control, and political dimensions of remote distribution, and their impact on the mobile computing actions. His current research concerns are the social and cultural aspects of globally distributed software engineering in which he is investigating the coordination and control challenges that are presented by the socio-cultural accidents associated with particular software engineering locations in the distribution. Gamel can be reached via e-mail at Gamel.Wiredu@ul.ie. 


\section{Part 4}

\section{Development Issues}

